\title{
IoT(Internet of Things)-based Underground Risk Assessment System Surrounding Water Pipes in Korea
}

\author{
Pill-Jae Kwak 1,1 , Sang-Hyuk Park ${ }^{1,2}$, Chang-Ho Choi ${ }^{1,3}$, Hyun-Dong Lee ${ }^{1,4}$, \\ Jae-Mo Kang 1,5 and In-Hwan Lee ${ }^{2}, 6$ \\ 'Korea Institute of Civil Engineering and Building Technology, 283, Goyandae- \\ Ro Ilsanseo-Gu, Goyang-Si, Gyeonggi-Do, 411-712, Korea \\ ${ }^{2}$ Electronics and Telecommunications Research Institute, 218, Gajeng-Ro, \\ Yuseong-Gu, Daejeon, 305-700, Korea
}

\begin{abstract}
IoT (Internet of Things) based underground risk assessment system surrounding water pipes enables an advanced monitoring and prediction for unexpected underground hazards such as abrupt road-side subsidence and urban sinkholes due to a leak in water pipes. For the development of successful assessment technology, the PSU (Pipe Safety Unit) is under development which detects the leakage and movement of water pipes. Then, the IoT-based underground risk assessment system surrounding water pipes will be proposed. The system consists of early detection tools for underground events and correspondence services, by analyzing leakage and movement data collected from PSU. These methods must be continuous and reliable, and cover certain block area ranging a few kilometers, for properly applying to regional water supply changes.
\end{abstract}

Keywords: water pipes, leakage, risk, assessment, subsidence, sinkhole

\section{Introduction}

A sinkhole is a hole or cavity in the ground that forms when water dissolves surface rock. In general, this surface rock is limestone, which is easily eroded by the groundwater flow. However, recent sinkholes are far from this reason. They occur with related to some artificial reasons such as careless construction for underground structures and damage or aging of underground pipelines. Recent sinkhole accidents occur due to less care during construction of underground structures such as regional water pipes, sewer line, subway tunnel and ground excavation for building construction. It means, as more underground construction undergoes, there is more chances that sinkholes open. About 40 cases of recent urban sinkholes were investigated that have occurred in South Korea since 1990's, and found out that the number of accidents dramatically increased from 2010 in which underground construction works in urban areas has grown.

1 Senior Researcher, Korea Institute of Civil Engineering and Building Technology (+82-31-910-0605, pjkwak@kict.re.kr)

2 Senior Researcher, Korea Institute of Civil Engineering and Building Technology (+82-31-910-0605, karasin811@kict.re.kr) Corresponding author

3 Researcher Fellow, Korea Institute of Civil Engineering and Building Technology (+82-31-910-0785, chchoi@kict.re.kr)

${ }_{4}$ Senior Researcher Fellow, Korea Institute of Civil Engineering and Building Technology (+31-910-0297, hdlee@,kict.re.kr)

5 Researcher, Korea Institute of Civil Engineering and Building Technology (+82-31-910-0556, jmkang@,kict.re.kr)

${ }^{6}$ Managing Director Principal Researcher, Electronics and Telecommunications Research Institute (+82-42860-6327, ihlee@etri.re.kr) 
Sinkholes (road side subsidence) sometimes happen when construction goes wrong, or because of aging and leakage of underground pipes. For aged underground pipes, they must be replaced. Local government continues replacement project of aged pipelines annually, especially sewer lines. With related to construction, more tight monitoring for ground movement must go with during construction. If there is suspicious ground settlement, site manager should do closer investigation immediately, then make a change of construction process and reinforce the ground as soon as possible. For this, proper regulation must be made in order to mandate contractors to actively remove any ground hazard.

IoT (Internet of Things) based underground risk assessment system surrounding water pipes enables an advanced monitoring and prediction for unexpected underground hazards such as abrupt road-side subsidence and urban sinkholes (road side subsidence) due to a leak in water pipes

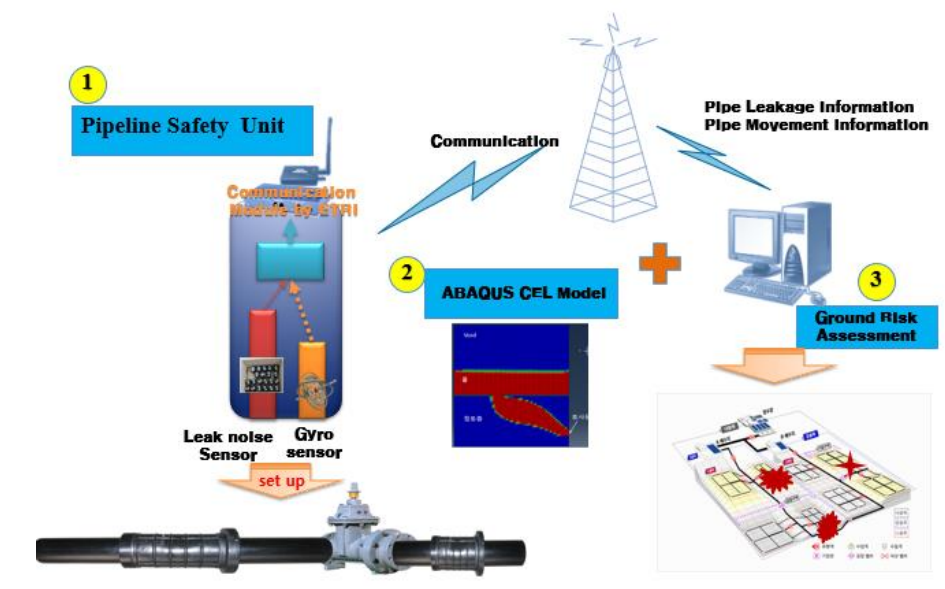

Figure 1. Underground Risk Assessment System Surrounding Water Pipes

\section{Development of PSU}

\subsection{Component of PSU}

PSU (Pipe Safety Unit) is a combination of leak detection sensor, gyroscope and accelerometer sensor unit. PSU can be a leak detection and location of the water supply pipe movement. PSU is divided into the sensor unit and the communication unit. Cable for connecting the sensor and the communication also is manufactured using a material of water-resistant. The sensor controller provides a function to filter the non-effective leak sound noise.

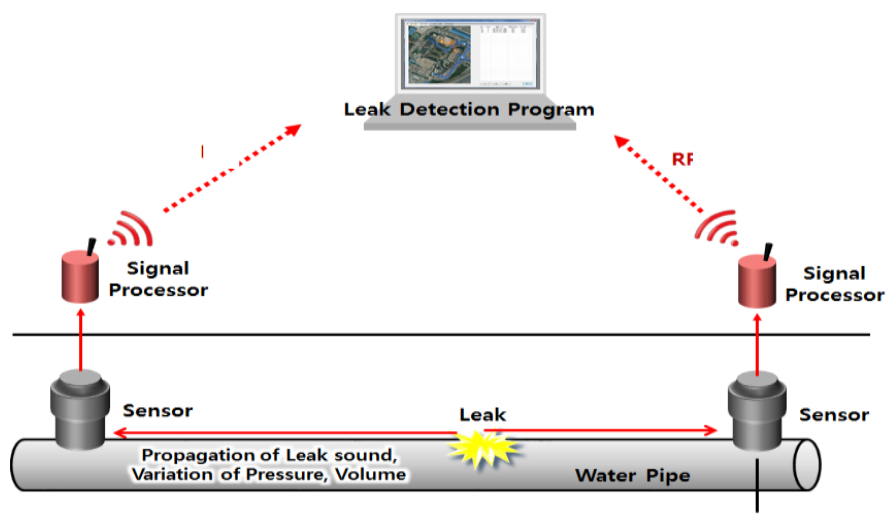

Figure 2. PSU Installation Diagram 


\subsection{Prototype of PSU Sensor Part}

The sensor part of PSU composes of stainless steel material of the outer casing and the piezoelectric element, a gyroscope sensor, an accelerometer sensor and sensor controller which filters sound leakage and positional displacement information. The sensor controller provides a function to filter the non-effective leak sound noise. The leakage detection sensor transforms the seismic-wave vibration caused by the leakage on the pipeline into an electrical signal using the piezoelectric effect of PZT ceramic. The detection logger consists of an amplifier that enhances the input signal from the sensor, band filter, an ADC and a microprocessor.

Table 1. Characteristic Properties of PSU

\begin{tabular}{|c|c|c|c|c|}
\hline $\begin{array}{l}\text { Lower } \\
\text { power } \\
\text { consumpti } \\
\text { on } \\
\end{array}$ & $\begin{array}{r}\text { Data } \\
\text { amount }\end{array}$ & $\begin{array}{l}\text { Data } \\
\text { interval }\end{array}$ & $\begin{array}{l}\text { Device } \\
\text { density }\end{array}$ & $\begin{array}{l}\text { Communicat } \\
\text { ion range }\end{array}$ \\
\hline 2 Years & $\begin{array}{l}10-20 \\
\text { Bytes }\end{array}$ & 5 Packets & $\begin{array}{l}\text { Max } \\
300 \mathrm{~m}\end{array}$ & $1 \mathrm{Km}$ \\
\hline $\begin{array}{l}\text { Communicat } \\
\text { ion } \\
\text { reliability }\end{array}$ & $\begin{array}{c}\text { System } \\
\text { management }\end{array}$ & Security & Topology & Usability \\
\hline $95 \%$ & $\begin{array}{c}\text { Node } \\
\text { error } \\
\text { detection } \\
\text { Monitorin } \\
\text { g battery } \\
\end{array}$ & $\begin{array}{c}\text { Encryptio } \\
\mathrm{n}\end{array}$ & $\begin{array}{c}\text { Star } \\
\text { Hop } \\
\text { extension }\end{array}$ & $\begin{array}{c}\text { Easy } \\
\text { maintenance }\end{array}$ \\
\hline
\end{tabular}
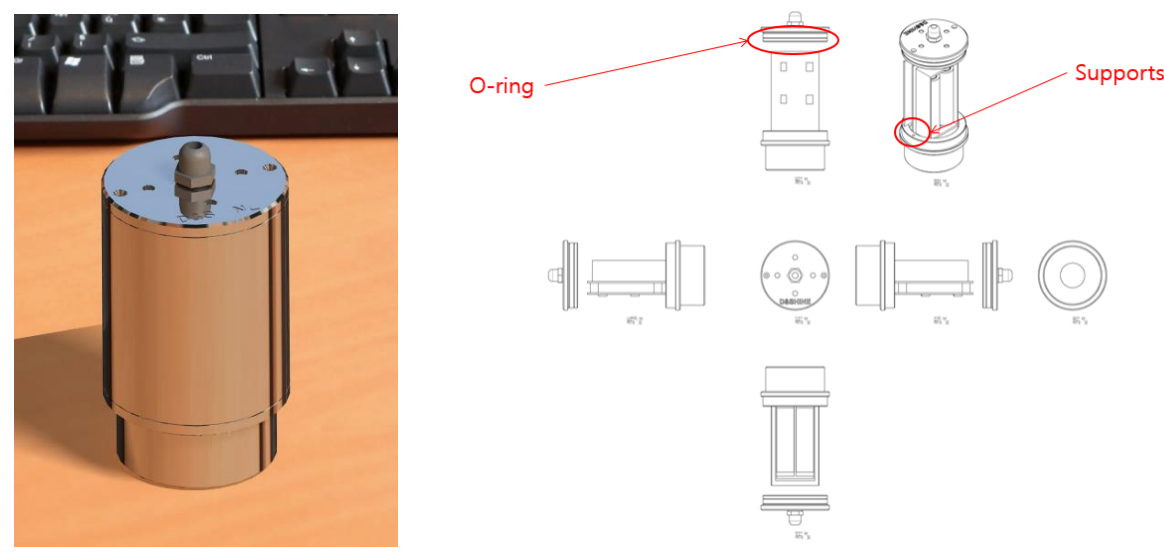

Figure 3. PSU Sensor Part

\subsection{Performance Test of PSU Sensor Part}

The performance of PSU piezoelectric sensor part was tested. After passing high and low filter is Figure 4. And after passing RMS to DC converter is Figure 5. The PSU piezoelectric sensor has proven to work well. 


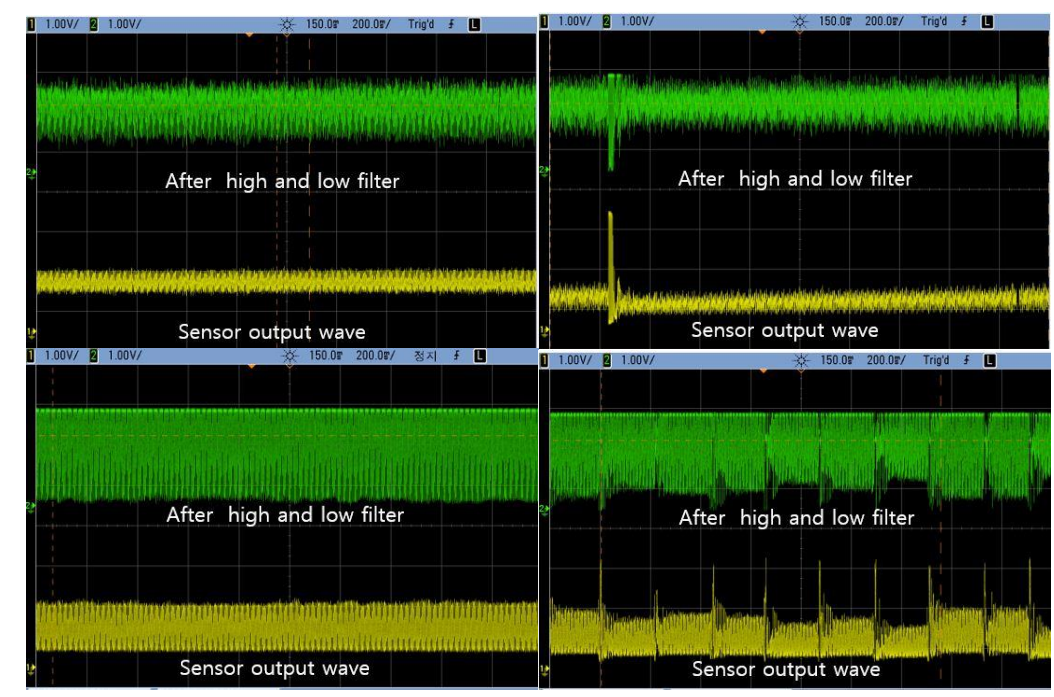

Figure 4. After Passing High And Low Filter
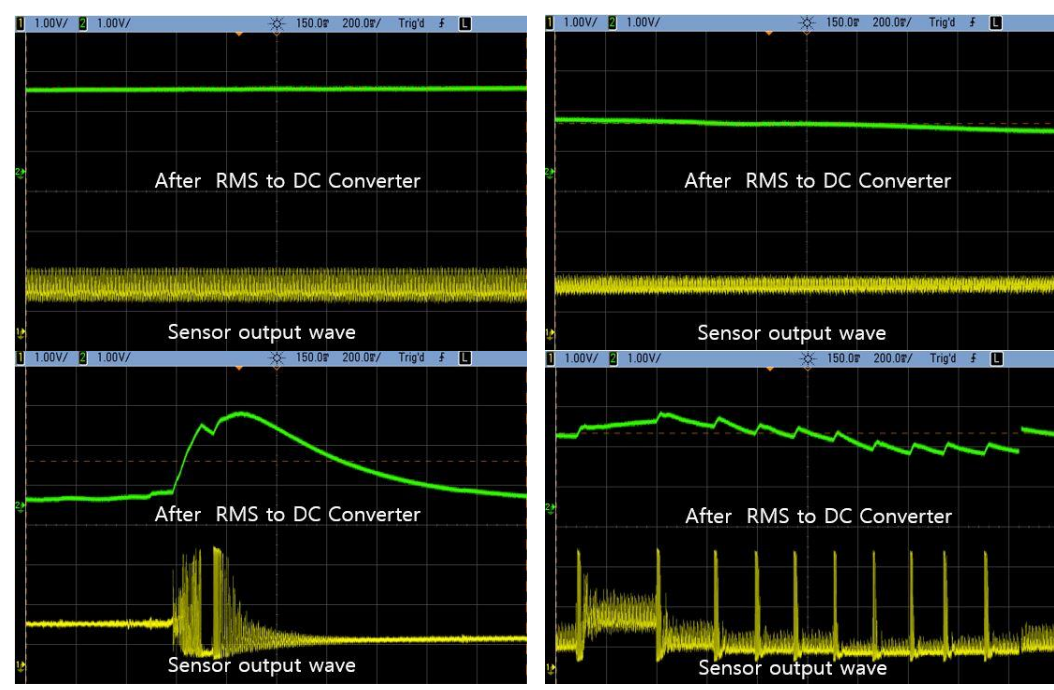

Figure 5. After Passing RMS to DC Converter

The performance of PSU gyroscope and accelerometer sensor part was tested. The PSU gyroscope and accelerometer sensor has proven to work well.
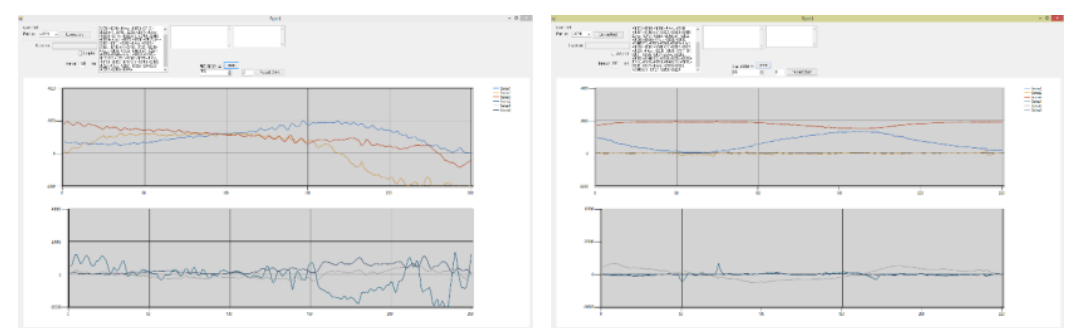

Figure 6. Gyroscope an Accelerometer Sensor Test

\subsection{Upgrade of Leakage Analysis Algorithm}

The field experiment was conducted in order to improve the leakage point analysis algorithms. Figure 7 is the schematic diagram of pipeline and sensor installation point. 
Table 2 is the specifications of pipeline.

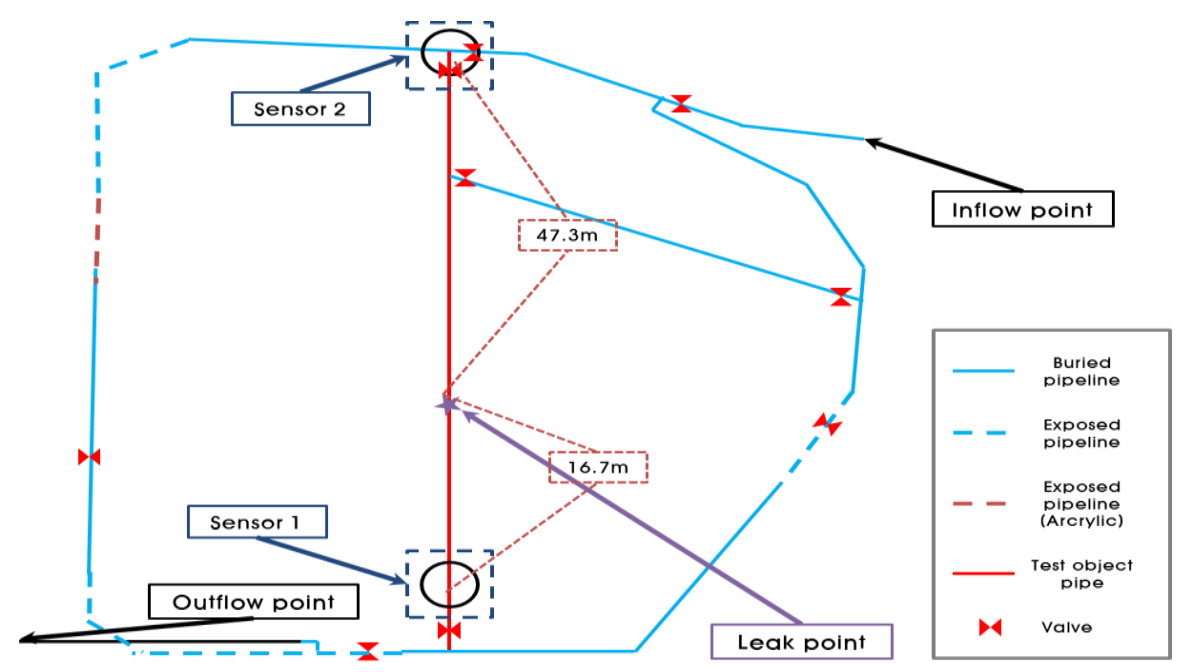

Figure 7. Schematic Diagram of Pipeline and Sensor Installation Point

Table 2. Specifications of Pipeline

\begin{tabular}{c|c|c|c|c|c}
\hline $\begin{array}{c}\text { Pipe } \\
\text { material }\end{array}$ & $\begin{array}{c}\text { Diamet } \\
\mathrm{er}\end{array}$ & $\begin{array}{c}\text { Lengt } \\
\mathrm{h}\end{array}$ & Depth & $\begin{array}{c}\text { Max. water } \\
\text { pressure }\end{array}$ & $\begin{array}{c}\text { Leak } \\
\text { hole size }\end{array}$ \\
\hline $\begin{array}{c}\text { Ductil } \\
\text { e cast } \\
\text { iron pipe }\end{array}$ & $\begin{array}{c}100 \\
\mathrm{~mm}\end{array}$ & $320 \mathrm{~m}$ & $2 \mathrm{~m}$ & $6 \mathrm{kgf} / \mathrm{cm}^{2}$ & $\begin{array}{c}0.1 \mathrm{~m} \\
\mathrm{~m}\end{array}$ \\
\hline
\end{tabular}
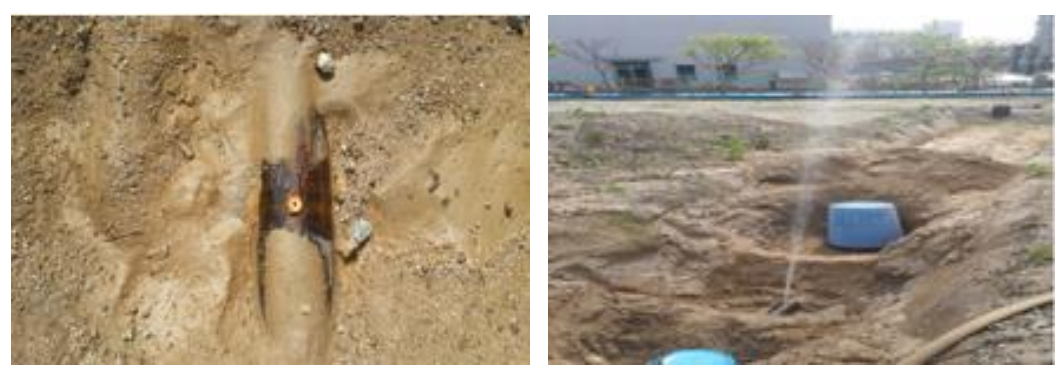

Figure 8. Leakage Hole and Water Leak

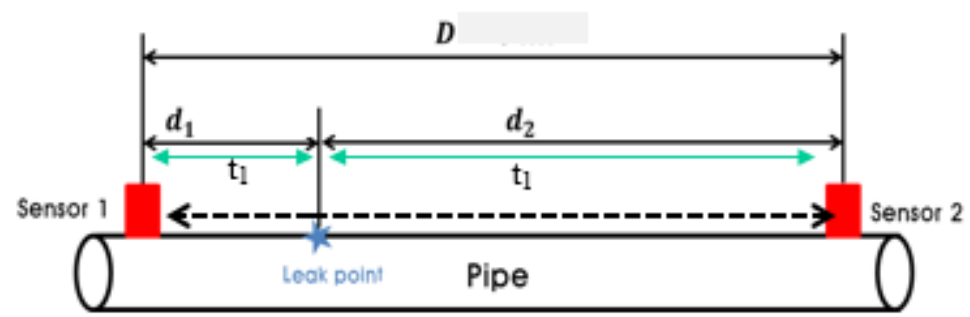

Figure 9. Leakage Point Analysis

Figure 9 is a concept of leakage point analysis. The leakage point can calculate by the following equation. 


$$
d_{1}=\frac{1}{2}(D-c \Delta t), \quad d_{2}=\frac{1}{2}(D+c \Delta t)
$$

$\mathrm{d}_{1}=$ distances of sensor 1 -from leak point $(\mathrm{m})$

$\mathrm{d}_{2}=$ distances of sensor 2 from leak point $(\mathrm{m})$

$\mathrm{c}=$ leak signal speed in water-filled pipe $(\mathrm{m} / \mathrm{s})$

$\Delta \mathrm{t}=$ Arrival time difference $\left(\mathrm{t}_{1}-\mathrm{t}_{2}\right)$

$\mathrm{D}=$ Distance between sensors

Figure 10 is a case of leakage point analysis. We are using a correlation method for leak detection on water pipelines. Simple water pipeline with a leak is measured by using two sensors. It is assumed that the leak location is between the two sensors with the distances of $\mathrm{d} 1$ and $\mathrm{d} 2$. If distance of $\mathrm{d} 1$ and $\mathrm{d} 2$ are difference, there must be different on an arrival time, or time delay between the two sensors when there is a leakage. It's difficult to pinpoint a pipe leakage location. We plan to get many data from field test.

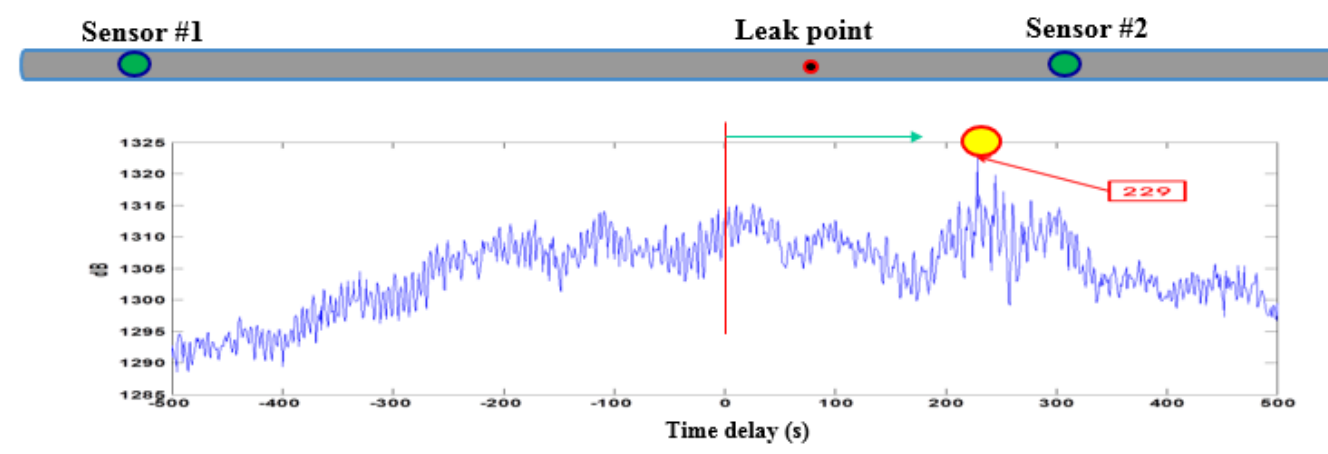

Figure 10. Result of Leakage Point Analysis

\section{Underground Assessment System Surrounding Water Pipes}

Underground risk assessment system surrounding water pipes predicts the occurrence of subsidence caused by the leakage and movement of water pipes. It consists of PSU (leak detection, gyroscope and accelerometer sensor) and PSU management and analysis technology. An analytical algorithm for analyzing the signal of leak detection and displacement is under development. It can be interpreted as a change of the position of leak location and channel using the analysis techniques. Figure 11 is a case study of the water pipe assessment system. With this system it is possible to monitor the problems of the water pipes. And the administrator might proceed the maintenance work. 


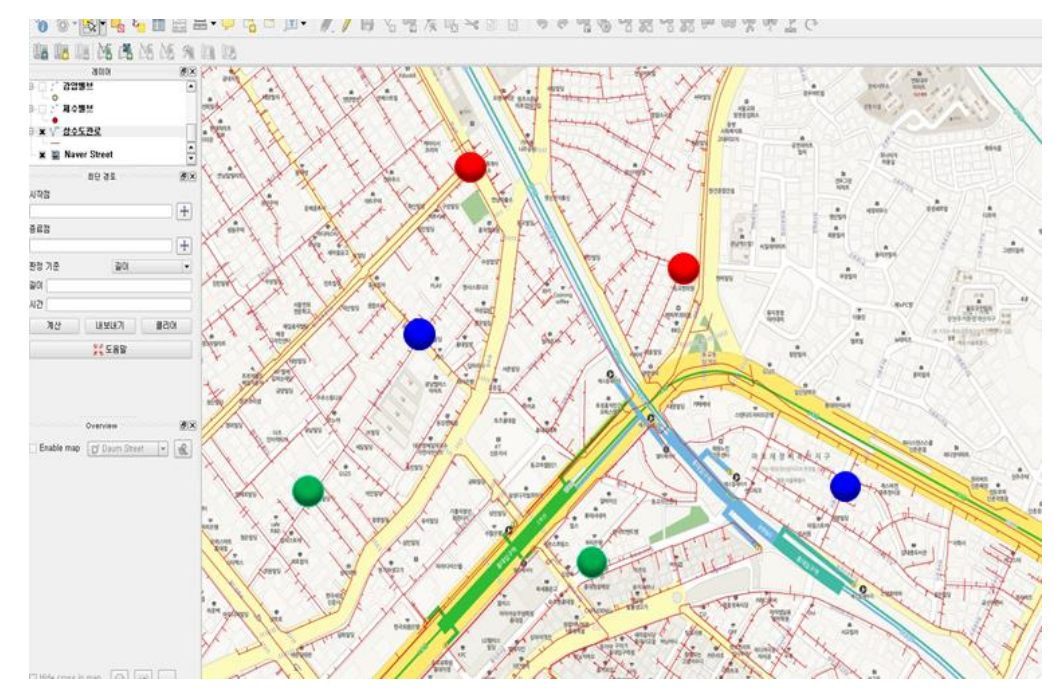

Figure 11. Water Pipe Underground Assessment System

The assessment algorithm will be developed based on the field simulation of leakage tests for water supply pipe lines. To relate the problem of water pipelines (leakage and positional displacement) and subsidence, the study of leakage amount and positional displacement grade should be conducted. Figure 12 is an estimation method of leakage amounts.

Possible sinkholes (road side subsidence) area is evaluated to more than allowable leak and where the position variation has occurred as determined by the simulation.

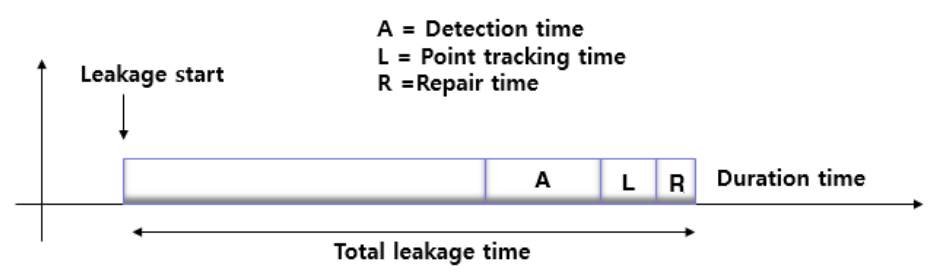

Figure 12. Estimation of Water Leakage Amounts

\section{Conclusion}

A technology for predicting sinkhole opening (road side subsidence) is under development. Final goal for the research program is to provide SRI (Sinkhole Risk Index) by monitoring tunnel, underground water pipes and sewer pipelines, and urban ground water flow. The research focuses on real-time underground monitoring based on IoT platform to build Big-Data, and then analyze the Big-Data to see the sinkhole hazard.

\section{Acknowledgment}

This subject is supported by Korea Ministry of Science, ICT and Future Planning as "Development of IoT-based Urban Underground Utility Monitoring and Management System'. 


\section{References}

[1] B. Ahmed, "Causes of cracking of culverts on filled soil and their performance after repair", Journal of civil Engineering, The Institution of Engineers Bangladesh Vol. CE 30 No. 1 (2002).

[2] I. Stoianov, L. Nachman, S. Madden and T. Tokmouline, "PIPENET: A wireless sensor network for pipeline monitoring", Proceedings of the International Symposiumon Information Processing in Sensor Networks, pp.264273 (2007).

[3] US, EPA: Control and Mitigation of Drinking Water Losses in Distribution System (EPA 816-R10-019) (2010).

[4] M.F. Ghazali, S.B.M. Beck, J.D. Shucksmith, J.B. Boxall and W.J. Staszewski, "Comparative study of instantaneous frequency based methods for leak detection in pipeline networks", Mechanical Systems and Signal Processing, Vol.29, pp.187-200 (2012).

[5] M. Fantozzi, A. Lambert and R. Liemberger, "Some examples of european water loss targets, and the law of unintended consequences", Proceeding of IWA Water Loss Europe (2012). 